9 - ORIGINAL ARTICLE

CLINICAL INVESTIGATION

\title{
Rapid on-site cytopathological examination (ROSE) performed by endosonagraphers and its improvement in the diagnosis of pancreatic solid lesions ${ }^{1}$
}

\author{
Ricardo Leite Ganc ${ }^{\mathrm{I}}$, Augusto Pincke Cruz Carbonari', Rogério Colaiacovo ${ }^{\mathrm{I}}$, Júlia Araujo ${ }^{\mathrm{III}}$, Sheila Filippi ${ }^{\mathrm{IV}}$, Rodrigo Altenfender \\ Silva $^{\mathrm{v}}$, Adhemar Monteiro Pacheco Junior ${ }^{\mathrm{V}}$, Lucio Giovanni Battista Rossini ${ }^{\mathrm{II}}$, Marc Giovannini ${ }^{\mathrm{VI}}$
}

\author{
DOI: http://dx.doi.org/10.1590/S0102-865020150070000009
}

${ }^{I} \mathrm{MD}$, Endoscopy Unit, Faculdade de Ciências Médicas da Santa Casa de São Paulo (FCMSCSP), Brazil. Conception and design the study, analysis of data, endoscopic procedures and on-site cytopathological examination, manuscript preparation.

${ }^{I I} \mathrm{PhD}$, Endoscopy Unit, FCMSCSP, Sao Paulo-SP, Brazil. Conception and design the study, critical revision, final approval.

II'Resident, French Brazilian Centre of Endoscopic Ultrasound (CFBEUS), Sao Paulo-SP, Brazil. Analysis of data.

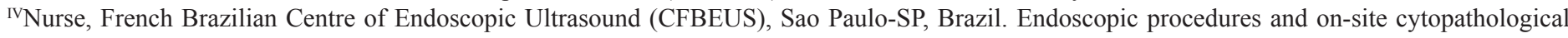
examination.

${ }^{v}$ Assistent Professor, Surgery Department, FCMSCSP, Chief of the Endoscopy Department of Sirio-Libanes Hospital Sao Paulo-SP, Brazil. Critical revision, final approval.

${ }^{\mathrm{V}} \mathrm{MD}$, Endoscopy Unit, Institut Paoli-Calmettes, Marseille, France. Conception and design the study, critical revision, final approval.

\begin{abstract}
PURPOSE: To evaluate the diagnosis improvement of EUS-FNA when using ROSE performed by the endosonographer.

METHODS: A retrospective study was conducted. A total of 48 pancreatic solid masses EUS-FNA were divided into two groups according to the availability of on-site cytology (ROSE) - the first 24 patients (group A-without ROSE) and the latter 24 cases (group B-with ROSE). Sensitivity, specificity, positive predictive value, negative predictive value, accuracy, complications and inadequacy rate of EUS-FNA were determined and compared.
\end{abstract}

RESULTS: Among the 48 EUS-FNA, the overall performance was: sensitivity 82\%; specificity 100\%; positive predictive value (PPV) $100 \%$; negative predictive value (NPV) $70 \%$ and accuracy $87 \%$. The sensitivity of the Group A was $71 \%$, versus $94 \%$ in-group B $(\mathrm{p}=0.61)$. Moreover, the negative predictive value was $58 \%$ versus $87 \%(\mathrm{p}=0.72)$. The accuracy rate increased from $79 \%$ to $96 \%$ $(\mathrm{p}=0.67)$ in the ROSE group. The number of punctures was similar between the groups. No major complications were reported.

CONCLUSION: Rapid on-site cytopathological examination, even when performed by the endosonographer, may improve the diagnostic performance in the diagnosis of solid pancreatic lesions, regardless of the slight increase in the number of punctures.

Key words: Endosonography. Pancreatic Neoplasms. Cell Biology. 


\section{Introduction}

Endoscopic ultrasound (EUS) was introduced in clinical practice in 1980 in order to improve the appreciation of the digestive tract walls and adjacent structures. Later, with the development of endoscopic ultrasound-guided fine needle aspiration (EUS-FNA), obtaining tissue specimen was made possible; thereby further improving its accuracy ${ }^{1-3}$.

EUS is the most accurate method for loco-regional staging of upper gastrointestinal cancers, with well-established clinical impact, influencing decision-making and patient management.

Furthermore, EUS-FNA proved to be a safe, accurate, and a reliable diagnostic procedure, with a high diagnostic and therapeutic yield ${ }^{4}$. The rapid on-site cytopathological examination (ROSE) during the procedure appears to have a significant impact on EUS-FNA success rates ${ }^{5}$.

The objectives of the study are to determine the overall performance of EUS-FNA in the diagnosis of solid pancreatic lesions in a Latin American EUS training center and to evaluate the diagnosis improvement of EUS-FNA when using ROSE performed by the endosonographer.

\section{Methods}

This is a single center prospectively enrolled retrospective study, including all patients referred for EUS examinations for pancreatic solid lesions from January 2009 to November 2011. The study was conducted at the FrenchBrazilian Centre of Endoscopic Ultrasonography (CFBEUS), located at the endoscopy unit of Santa Casa of Sao Paulo Hospital, Brazil.

After obtaining formal informed written consent, an anesthesiologist sedated all patients. EUS-FNA was performed by using an EG-530UT linear echoendoscope and SU-7000 ultrasonic processor (Fujinon, Saitama, Japan) and 22-G EchoTip ${ }^{\circledR}$ needle (Cook Medical Inc, Limerick, Ireland).

During the study period, a total of 963 EUS examinations were performed, of which, 71 EUS-FNA of suspected pancreatic lesions were evaluated, including 48 solid lesions and 23 cystic lesions.

The present article regards pancreatic solid lesions, therefore, only the 48 EUS-FNA of such lesions were included. Single and multiple FNA passes (1 to 7 passes) were done in the first 24 EUS-FNA cases (group A) (Figure 1). For the latter 24 cases (group B), EUS-FNA passes were performed until ROSE evaluation confirmed the presence of a sufficient number of representative lesion cells. The same endosonographer performed the fine needle aspirates and prepared the cytology slides using the Diff-Quik ${ }^{\circledR}$ stain set $^{6}$. The tissue specimens obtained were also immediately formalin-fixed for further cellblock study.

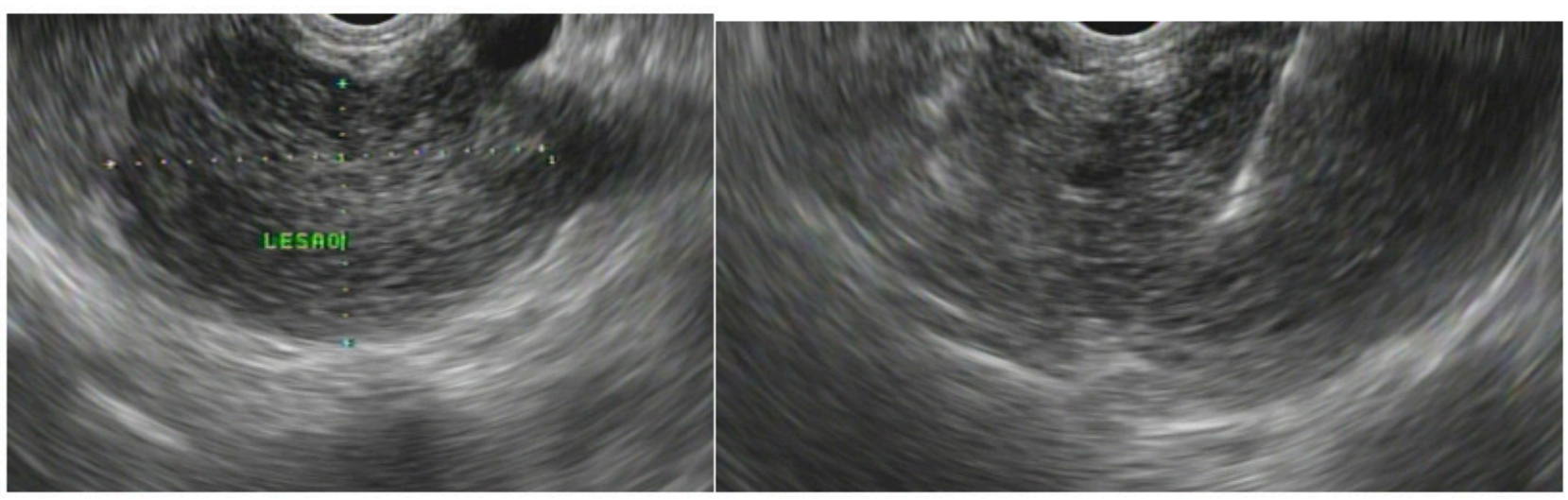

FIGURE 1 - EUS-FNA of a pancreatic mass.

The endosonographer had sufficient experience in more than 300 pancreatic and biliar EUS-FNA procedures and underwent formal cytology training with the cytopathologist. This included at least 30 hours of theoretical-practical and review of slides, with the board-certified cytopathologist demonstrating examples of adequate, inadequate, benign and malignant slides (Figure 2). 


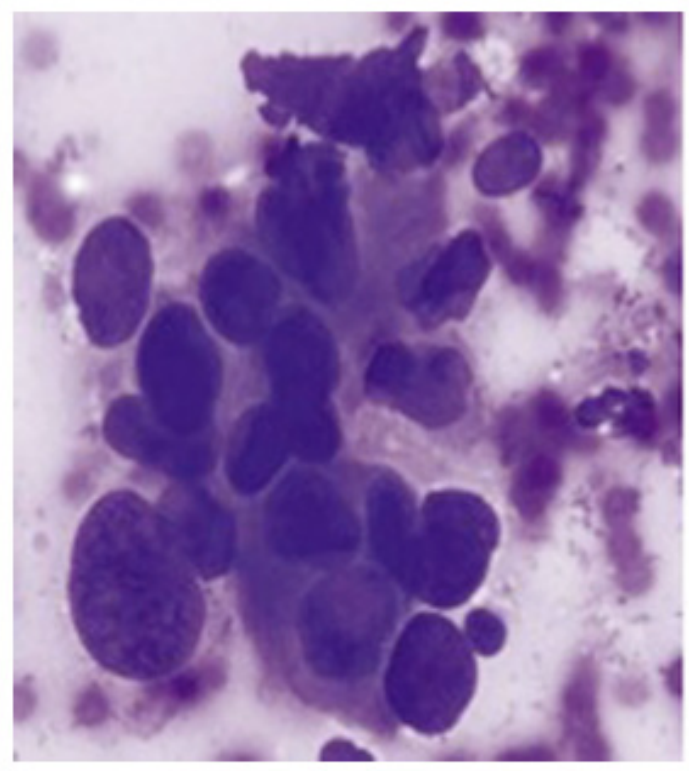

FIGURE 2 - Cytology slide: pancreatic adenocarcinoma (Diff-Quik $\left.\operatorname{stain}^{\circledR}\right)$.

For the EUS-FNA procedures, the standard suction technique was used, with the $10 \mathrm{~mL}$ syringe that is part of the EchoTip $^{\circledR}$ needle kit.

The final diagnosis was based on the examination of the results of the slides, the cell-block and surgical pathology specimens. Technical failure was considered when there was insufficient aspirated material to determine a final diagnosis, according to the pathologist. and this datum was used to calculate the inadequacy rate.

The definition of complications followed the same criteria used by the American Society for Gastrointestinal Endoscopy (ASGE) and European Society of Gastrointestinal Endoscopy (ESGE) guidelines ${ }^{7,8}$

All patients signed an informed consent and the ethics committee of the institution approved the study.

\section{Statistical analysis}

Initially, all variables were analyzed descriptively. For quantitative variables, the analysis was done through observation of minimum and maximum values and the calculation of mean values, standard deviations. For qualitative variables, we calculated absolute and relative frequencies. To compare the proportions of failures of the methods we used the Fisher's Exact Test. To study the efficiency of the methods we analyzed the values of sensitivity, specificity, accuracy, positive and negative predictive values. The significance level used for the tests was $5 \%$.

\section{Results}

Among the 48 EUS-FNA of pancreatic solid masses, the overall performance was: sensitivity $82 \%$; specificity $100 \%$; positive predictive value (PPV) 100\%; negative predictive value (NPV) $70 \%$ and accuracy $87 \%$.

The sensitivity of the Group A was $71 \%$, versus $94 \%$ on group B ( $p=0.61)$. The specificity of both groups was $100 \%$, as well as the positive predictive value. Moreover, the negative predictive value was $58 \%$ versus $87 \%(\mathrm{p}=0.72)$. The accuracy rate increased from $79 \%$ to $96 \%(\mathrm{p}=0.67)$ on the ROSE group. These results can be appreciated in Table 1.

TABLE 1 - Performance for EUS-FNA of pancreatic solid lesions.

\begin{tabular}{lccccc}
\hline TABLE 1 & SENSITIVITY & ESPECIFICITY & PPV & NPV & ACCURACY \\
\hline OVERALL PERFOMANCE & $82 \%$ & $100 \%$ & $100 \%$ & $70 \%$ & $87 \%$ \\
GROUP A (WITHOUT ROSE) & $71 \%$ & $100 \%$ & $100 \%$ & $58 \%$ & $79 \%$ \\
GROUP B (WITH ROSE) & $94 \%$ & $100 \%$ & $100 \%$ & $87 \%$ & $96 \%$ \\
\hline
\end{tabular}

$* \mathrm{PPV}=$ positive predictive value, $\mathrm{NPV}=$ negative predictive value

The inadequacy rate (insufficient material) on Group A was $20.8 \%$ (5/24 patients) and 4.15\% (1/24 patients) in-group $\mathrm{B}(\mathrm{p}=0.19)$. All of these patients died of advanced disease and were considered false negative (6/48-12.5\%). In-group A, the number of punctures ranged from 1 to 6 with a mean value of 3.5. In-group $B$, the number of punctures ranged from 3 to 8 , with a mean value of 4.3 . These results were not statistically significant. There were no major complications in this study.
Two patients in group A (8.3\%) and three (12.5\%) in group $\mathrm{B}$ with immediate mild abdominal pain, which resolved with analgesics and did not prolong hospital stay. Two patients $(8.3 \%)$ in each group complained of soar throat for a few days that resolved with oral Benzocaine.

The most common diagnosis is the pancreatic adenocarcinoma, followed by the results of non-neoplastic diseases such as pancreatitis and normal pancreatic tissue (Figure 3). 


\section{EUS-FNA - Solid pancreatic lesions}

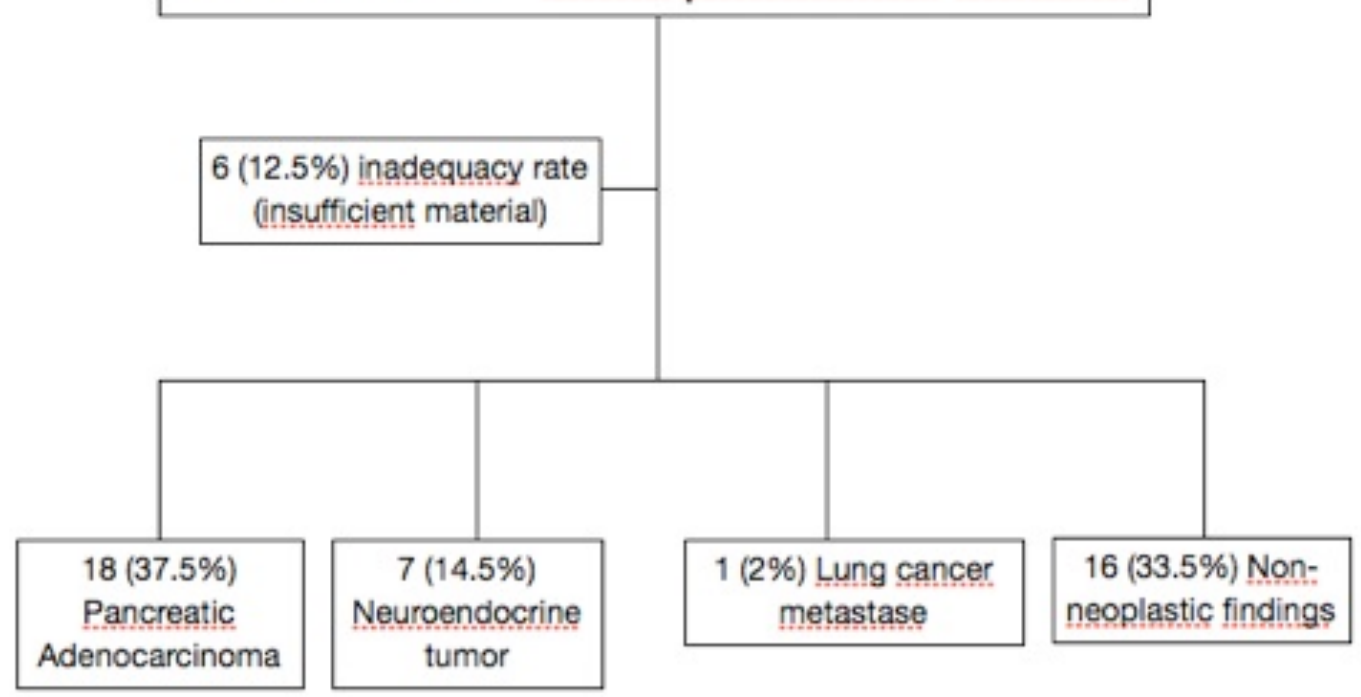

FIGURE 3 - Final histological diagnosis of the punctured lesions.

\section{Discussion}

Pancreatic adenocarcinoma is the second most common gastrointestinal malignancy and the fourth leading cause of cancerrelated mortality in the United States ${ }^{9}$.

EUS has well-defined accuracy in GI malignancies stages and is the most accurate method in establishing the presence of pancreatic lesions, but cannot alone, reliably differentiate benign from malignant lesions. Consequently, pathological examination is often required to establish a definitive diagnosis ${ }^{10-13}$.

EUS-guided fine needle aspiration (EUS-FNA) was first described in 1991 for the evaluation of gastric sub-mucosal lesions and pancreatic cancer ${ }^{14-15}$.

For EUS-FNA of pancreatic lesions, many different needles can be used, nonetheless. The results don't appear to change much and the complication rate may increase when using a $19 \mathrm{G}$. Therefore we adopted the $22 \mathrm{G}$ needle for this study.

Even though, nowadays different suction techniques may be applied, such as slow-pull, or no suction at all, at the time of the beginning of the protocol, that was not an issue and it was not considered as a variable then.

There are studies that have examined the improvement of diagnostic ability of EUS-FNA without on-site cytopathologist, but with the immediate microscopic inspection by endosonographers ${ }^{16-17}$. In a retrospective study, Savoy et al. compared the abilities of endosonographers and cytotechnologists in the immediate evaluation of microscopic inspection. The respective accuracies were of $70 \%$ and $89 \%{ }^{16}$. In our study, the ROSE-group accuracy was $96 \%$, which can be considered similar to the cytotechnologists on Savoy's study.

In contrast, Erickson et al. ${ }^{18}$ and Nasuti et al. ${ }^{19}$ showed that the absence of ROSE at all, resulted in poor diagnostic accuracy as well as increased procedure time, number of needles used, and overall examination costs.

More recently, Iglesias-Garcia et al. demonstrated that ROSE decreased the number of passes with the EUS needle, the inadequacy of the collected specimen, as well as was associated with a significantly higher diagnostic sensitivity (96.2 vs. $78.2 \%$; $\mathrm{p}=0.002$ ) and overall accuracy ( 96.8 vs. $86.2 \% ; \mathrm{P}=0.013$ ) for malignancy ${ }^{20}$.

In our study, after ROSE performed by the endosonographer, the sensitivity increased from $71 \%$ to $94 \%(p=0.61)$, the negative predictive value from $58 \%$ to $87 \%(\mathrm{p}=0.72)$ and the accuracy from $79 \%$ to $96 \%(\mathrm{p}=0.67)$. The insufficient aspirated material decreased from $20.8 \%$ to $4.1 \%(p=0.19)$. Although, not statistically significant, ROSE increased the accuracy of the method and reduced technical failure. Iglesias-Garcia et al. observed the same pattern in the previously quoted study, although their inadequacy rates were lower than ours altogether $(12.6 \%$ without ROSE and $1 \%$ with ROSE). We could argue whether the pathologists of their group are better acquainted with pancreatic cytology or that technically the endosonographer of our study is less experienced. 
With that in mind and using our data as a starting point, we have an ongoing prospective study in our center, on ROSE, where we intend to enroll a larger sample size.

Nonetheless, our data is similar to other articles in this field, such as the meta-analysis recently published by Hewitt et $a l .{ }^{21}$. In his study the pooled sensitivity for malignant cytology was $85 \%$ and pooled specificity was $98 \%$.

One may wonder how we managed, in a retrospective study, to have exactly 24 patients in each group. The manner we chose to draw the protocol explains that. The idea was to finish the study in three years. When we reached 18 months in the study, we concluded the first group. The number of patients enrolled was 24. Therefore, we decided to perform ROSE, in the following 24 patients. The data acquired was analyzed retrospectively. That's why, this may be called a prospectively enrolled retrospective study.

In the present article, the appliance of ROSE caused the mean number of punctures to increase from 3.5 to 4.3. Even though this was not significant, it was somehow unexpected, since ROSE is thought to decrease the number of punctures needed to confirm the diagnosis, as suggested by Iglesias-Garcia ${ }^{20}$. Some may argue that the increase in the number of punctures, might justify the better result by itself, leaving no benefit for the ROSE procedure. We do not believe that, because, the number of punctures did not differ that much (3.5 - 4.3) and was far from being significant.

On the other hand, the apparent improvement in performance and the decrease of inadequate material samples justifies the use of ROSE.

There were no major complications in this study. As previous articles demonstrated, EUS-FNA is a safe procedure with a complication rate of approximately 1-2\%. Major complications include infection, bleeding, and acute pancreatitis and are more frequent for EUS-FNA of cystic compared with solid lesions ${ }^{7,8,21}$.

The main difference between this study and the others is the fact that, the number of punctures needed for diagnosis with ROSE did not decrease, on the contrary. Nonetheless, the apparent improvement in performance, suggests that this is not an issue, as long as this trend proves to be true. Most likely, larger and multicenter trials might be able to do so.

\section{Conclusion}

Rapid on-site cytopathological examination, even when performed by the endosonographer, may improve the diagnostic performance in the diagnosis of solid pancreatic lesions, regardless of the slight increase in the number of punctures.

\section{References}

1. Ganc AJ, Ganc RL. Ultra-som endoscópico. Histórico, princípios físicos e equipamentos. In: Cordeiro FT, Magalhães AF, Prolla JC, Quilici FA. Endoscopia digestiva. São Paulo: MEDSI; 2000. p.292-301.

2. Ganc AJ, Ganc RL, Rossini LG. Ultra-sonografia endoscópica em gastroenterologia. In: Mincis M. Gastroenterologia e hepatologia: diagnóstico e tratamento. São Paulo: Lemos editorial; 2002. p.65-79.

3. DiMagno EP, Buxton JL, Regan PT, Hattery RR, Wilson DA, Suarez JR, Green PS. Ultrasonic endoscope. Lancet. 1980 Mar 22;1(8169):629-31. PMID: 6102631.

4. Yoshinaga S, Suzuki H, Oda I, Saito Y. Role of endoscopic ultrasound-guided fine needle aspiration (EUS-FNA) for diagnosis of solid pancreatic masses. Dig Endosc. 2011 May;23 Suppl 1:2933. doi: 10.1111/j.1443-1661.2011.01112.x.

5. Klapman JB, Logrono R, Dye CE, Waxman I. Clinical impact of onsite cytopathology interpretation on endoscopic ultrasound-guided fine needle aspiration. Am J Gastroenterol. 2003 Jun;98(6):1289-94. PMID: 12818271.

6. Skipper R, DeStephano D. Diff-Quik stain. J Histotechnol. 1989;12(4):303.

7. Eisen GM, Dominitz JA, Faigel DO, Goldstein JA, Petersen BT, Raddawi HM, Ryan ME, Vargo JJ 2nd, Young HS, WheelerHarbaugh J, Hawes RH, Brugge WR, Carrougher JG, Chak A, Faigel DO, Kochman ML, Savides TJ, Wallace MB, Wiersema MJ, Erickson RA; American Society for Gastrointestinal Endoscopy. Guidelines for credentialing and granting privileges for endoscopic ultrasound. Gastrointest Endosc. 2001 Dec;54(6):811-4. PMID: 11726873

8. Polkowski M, Larghi A, Weynand B, Boustière C, Giovannini M, Pujol B, Dumonceau JM; European Society of Gastrointestinal Endoscopy (ESGE). Learning, techniques, and complications of endoscopic ultrasound (EUS)-guided sampling in gastroenterology: European Society of Gastrointestinal Endoscopy (ESGE) Technical Guideline. Endoscopy. 2012 Feb;44(2):190-206. doi: 10.1055/s0031-1291543.

9. Li J, Ng J, Allendorf J, Saif MW. Locally advanced pancreatic adenocarcinoma: are we making progress? Highlights from the "2011 ASCO Annual Meeting”. Chicago, IL, USA; June 3-7, 2011. JOP. 2011 Jul 8;12(4):347-50. PMID: 21737893.

10. Erickson RA, Garza AA. Impact of endoscopic ultrasound on the management and outcome of pancreatic carcinoma. Am J Gastroenterol. 2000 Sep;95(9):2248-54. PMID: 11007225.

11. Krinsky ML, Binmoeller KF. EUS-guided investigational therapy for pancreatic cancer. Gastrointest Endosc. 2000 Dec;52(6 Suppl):S35-8. PMID: 11115946.

12. Chhieng DC, Jhala D, Jhala N, Eltoum I, Chen VK, Vickers S, Heslin MJ, Wilcox CM, Eloubeidi MA. Endoscopic ultrasoundguided fine-needle aspiration biopsy: a study of 103 cases. Cancer. 2002 Aug 25;96(4):232-9. PMID: 12209665.

13. Othman MO, Wallace MB. The role of endoscopic ultrasonography in the diagnosis and management of pancreatic cancer. Gastroenterol Clin North Am. 2012 Mar;41(1):179-88. doi: 10.1016/j. gtc.2011.12.014

14. Caletti GC, Brocchi E, Ferrari A, Bonora G, Santini D, Mazzoleni G, Barbara L. Guillotine needle biopsy as a supplement to endosonography in the diagnosis of gastric submucosal tumors. Endoscopy. 1991 Sep;23(5):251-4. PMID: 1743123.

15. Vilmann P, Jacobsen GK, Henriksen FW, Hancke S. Endoscopic ultrasonography with guided fine needle aspiration biopsy in pancreatic disease. Gastrointest Endosc. 1992 Mar-Apr;38(2):172-3. PMID: 1568614. 
Ganc RL et al.

16. Savoy AD, Raimondo M, Woodward TA, Noh K, Pungpapong S, Jones AD, Crook J, Wallace MB. Can endosonographers evaluate on-site cytologic adequacy? A comparison with cytotechnologists. Gastrointest Endosc. 2007 Jun;65(7):953-7. PMID: 17531627.

17. Nguyen YP, Maple JT, Zhang Q, Ylagan LR, Zhai J, Kohlmeier C, Jonnalagadda S, Early DS, Edmundowicz SA, Azar RR. Reliability of gross visual assessment of specimen adequacy during EUSguided FNA of pancreatic masses. Gastrointest Endosc. 2009 Jun;69(7):1264-70. doi: 10.1016/j.gie.2008.08.030.

18. Erickson RA, Sayage-Rabie L, Beissner RS. Factors predicting the number of EUS-guided fine-needle passes for diagnosis of pancreatic malignancies. Gastrointest Endosc. 2000 Feb;51(2):18490. PMID: 10650262.

19. Nasuti JF, Gupta PK, Baloch ZW. Diagnostic value and costeffectiveness of on-site evaluation of fine-needle aspiration specimens: review of 5,688 cases. Diagn Cytopathol. 2002 Jul;27(1):1-4. PMID: 12112806.

20. Iglesias-Garcia J, Dominguez-Munoz JE, Abdulkader I, LarinoNoia J, Eugenyeva E, Lozano-Leon A, Forteza-Vila J. Influence of on-site cytopathology evaluation on the diagnostic accuracy of endoscopic ultrasound-guided fine needle aspiration (EUS-FNA) of solid pancreatic masses. Am J Gastroenterol. 2011 Sep;106(9):170510. doi: 10.1038/ajg.2011.119.

21. Hewitt MJ, McPhail MJ, Possamai L, Dhar A, Vlavianos P, Monahan KJ. EUS-guided FNA for diagnosis of solid pancreatic neoplasms: a meta-analysis. Gastrointest Endosc. 2012 Feb;75(2):319-31. doi: 10.1016/j.gie.2011.08.049.

\section{Correspondence:}

Ricardo Leite Ganc

Rua Escobar Ortiz, 444/21

Tel.: (55 11)3887-5400/99101-9999

Fax: (55 11)3884-9377

ricardoganc@gmail.com

Received: March 15, 2015

Review: May 13, 2015

Accepted: June 17, 2015

Conflict of interest: none

Financial source: none

${ }^{1}$ Research performed at Endoscopy Unit, French-Brazilian Centre of Endoscopic Ultrasonography (CFBEUS), Faculdade de Ciências Médicas da Santa Casa de São Paulo (FCMSCSP), Brazil. 